\title{
Characteristics of the lithium-mediated proximal US-preexposure effect in flavor-aversion conditioning
}

\author{
MICHAEL R. BEST \\ Southern Methodist University, Dallas, Texas 75275 \\ and \\ MICHAEL DOMJAN \\ University of Texas at Austin, Austin, Texas 78712
}

\begin{abstract}
Taste-aversion learning in rats is disrupted if the subjects are exposed to the unconditioned stimulus (US) shortly before the conditioning trial but not if this single US preexposure treatment occurs 1 day or more before conditioning. Several characteristics of this proximal US-preexposure phenomenon were explored. Experiment 1 showed that the time course of the interference with conditioning is directly related to the preexposure drug dose. Experiment 2 demonstrated that the interference effect is evident even if the test for aversion learning is conducted following a drug injection, thereby minimizing stimulus generalization decrement for the preexposed subjects. Finally, Experiment 3 showed that disruption of the contingent relationship between tastes and drug effects is probably not responsible for the proximal US-preexposure phenomenon because the interference with conditioning occurs regardless of whether or not the preexposure drug treatment is paired with a novel flavor. These findings, together with previous research, demonstrate the remarkably robust character of the proximal US-preexposure phenomenon.
\end{abstract}

Preconditioning administration of lithium chloride reduces the effectiveness of lithium as the unconditioned stimulus (US) in a flavor-aversion conditioning procedure (see Gamzu, 1977, for a review). One set of procedures which reliably produces this phenomenon involves multiple exposures to lithium prior to one or more flavor-lithium pairings. The deleterious effect of such repeated preconditioning lithium treatments occurs even if the preexposure drug injections are given several days before conditioning. Consequently, this source of interference with conditioning has been termed the durable or remote US-preexposure effect (Domjan, 1978; Domjan \& Best, 1977).

A single preconditioning exposure to lithium can also interfere with subsequent lithium-motivated aversion conditioning, but such a disruption typically occurs only if the preexposure injection is given less than $24 \mathrm{~h}$ before conditioning. Domjan and Best (1977), for example, observed that an injection of lithium significantly attenuated the conditioning of a

The research was supported by Grants MH 30788-01 from the Public Health Service and BNS 77-01552 from the National Science Foundation. The technical assistance of Paul E. Johnson is gratefully acknowledged. Requests for reprints should be addressed to Michael R. Best, Department of Psychology, Southern Methodist University, Dallas, Texas 75275. lithium-mediated saccharin aversion if the drug preexposure preceded the conditioning trial by $30 \mathrm{~min}$, but not if this single lithium preexposure was given 1 or more days before conditioning. It was also observed that the conditioning decrement resulting from one preconditioning lithium injection decreased systematically as the preexposure-to-conditioning interval was increased. This short-term preexposure phenomenon was consequently termed the transient or proximal US-preexposure effect (Domjan, 1978; Domjan \& Best, 1977) to differentiate it from the other, more durable effect.

The present experiments were designed to specify further the boundary conditions of the proximal preexposure phenomenon. In Experiment 1, various drug preexposure doses were tested to evaluate how the temporal gradient of interference is related to this variable. Experiment 2 was performed to determine whether or not the proximal US-preexposure effect is due to a generalization decrement produced by changes in drug state from conditioning to testing. This was done by conducting the postconditioning test while subjects were under the influence of the same drug that had been administered shortly before the conditioning trial. Finally, Experiment 3 was designed to evaluate whether or not the proximal US-preexposure effect is due to disruption of the 
contingent relationship between tastes and drug effects caused by giving the preexposure drug treatment without prior exposure to a novel taste. Independent groups in Experiment 3 received proximal lithium preexposure with and without pairing with a novel flavor, to determine how this manipulation influences the interference with taste-aversion learning.

\section{EXPERIMENT 1}

Using a moderate dose of lithium $(1.8 \mathrm{mEq} / \mathrm{kg})$, Domjan and Best (1977) preexposed groups of rats on a single occasion $30 \mathrm{~min}, 360 \mathrm{~min}, 1$ day, or 2 days prior to a saccharin-lithium conditioning trial. Under these circumstances, a significant conditioning decrement was observed when lithium preceded the saccharin-aversion trial by $30 \mathrm{~min}$ but not if $360 \mathrm{~min}$, 1 day, or 2 days elapsed between preexposure and conditioning. In contrast to the rapid decay of the interference effect reported by Domjan and Best (1977), Cannon, Berman, Baker, and Atkinson (1975) observed a conditioning decrement $24 \mathrm{~h}$ after preexposure to a single $2.4-\mathrm{mEq} / \mathrm{kg}$ lithium injection, and Braveman (1975) observed interference with conditioning 10 days after one $3.0-\mathrm{mEq} / \mathrm{kg}$ lithium injection. Since these investigators used higher drug preexposure doses than that used by Domjan and Best, the more durable character of the interference they observed may have been related to this factor.

Experiment 1 was designed to provide systematic evidence of the relationship between the temporal gradient of the proximal preexposure effect and the preexposure drug dose. Independent groups of rats were preexposed to lithium $90 \mathrm{~min}, 360 \mathrm{~min}$, or 1 day before taste-aversion conditioning. For some subjects, the preexposure injection was $1.8 \mathrm{mEq} / \mathrm{kg}$ lithium, whereas for others it was $3.0 \mathrm{mEq} / \mathrm{kg}$ lithium. The degree of aversion animals learned in these groups was then compared to the aversion learning of animals which received saccharin conditioning without prior lithium treatment.

\section{Method}

Forty-six female and 29 male Sprague-Dawley rats, 45-55 days old, served as subjects. They had been born in the laboratory and were individually housed in standard wire-mesh cages with continuous access to Purina Rat Chow throughout the experiment. Illumination was provided 8 a.m.-8 p.m. each day, and experimental manipulations were always administered during the light hours. Access to water was restricted to 30 min daily, starting 9-10 days before the saccharin conditioning trial. Subjects were also adapted to handling during this initial phase of the experiment.

On the saccharin conditioning day, following $24 \mathrm{~h}$ water deprivation, all subjects were allowed to drink a .15\% (weight/volume in tap water) solution of sodium saccharin for $20 \mathrm{~min}$ or until they had consumed $3 \mathrm{ml}$, whichever occurred first. Forty minutes after the beginning of this saccharin-access period, each subject received a $1.8-\mathrm{mEq} / \mathrm{kg}$ intraperitoneal (IP) injection of $.15 \mathrm{M}$ lithium chloride. The various groups differed only in terms of when and what injection they received before the saccharin presentation. Group 1.8-1 Day (4 males, 7 females) and Group 3.0IDay (4 males, 7 females) received a $1.8-$ and a $3.0-\mathrm{mEq} / \mathrm{kg}$, IP, injection of lithium, respectively, 1 day before the saccharin access. (The daily 30-min access to water was given $2 \mathrm{~h}$ after this preexposure injection.) Group 1.8-360 (4 males, 7 females) and Group 3.0-360 (4 males, 6 females) received 1.8 and 3.0$\mathrm{mEq} / \mathrm{kg}$ injections of lithium, respectively, $360 \mathrm{~min}$ before saccharin access, and Groups 1.8-90 (5 males, 6 females) and 3.0-90 (4 males, 6 females) received their preexposure injection $90 \mathrm{~min}$ before their flavor exposure. The seventh group of subjects ( 4 males, 7 females) served as the taste-aversion control (TAC) group; these subjects were not preexposed to lithium, but received an injection of isotonic saline $90 \mathrm{~min}$ before saccharin access instead, with 6 subjects being given $1.8 \mathrm{mEq} / \mathrm{kg}$ and 5 subjects being given $3.0 \mathrm{mEq} / \mathrm{kg}$. None of the subjects received access to water on the conditioning day, but the $30-\mathrm{min}$ daily water presentations were resumed the next day.

Six days after saccharin conditioning, all subjects were tested for their aversion to the saccharin solution. Following $24 \mathrm{~h}$ of water deprivation, the flavored solution was presented for $20 \mathrm{~min}$ in the absence of any other fluids, and the amount ingested was recorded to the nearest $1 / 4 \mathrm{ml}$.

Except when removed for handling and injection, the subjects remained in their home cages throughout the experiment. The saccharin solution was presented in glass graduated centrifuge tubes which were provided with rubber stoppers and stainless steel drinking spouts and were clipped to the home cages when required. The data from one male in Group 1.8-1Day and one female in each of the Groups 1.8-90, 1.8-360, 3.0-1Day, and TAC were discarded because the subjects either died or developed severe respiratory disease, or because an error had been made in administration of their procedure.

\section{Results}

Only four subjects failed to drink the allotted $3 \mathrm{ml}$ saccharin on the conditioning day. One of these was in Group TAC and drank $1.75 \mathrm{ml}$, one was in Group 1.8-90 and drank $2.0 \mathrm{ml}$, and two were in Group 3.0-90 and drank 2.5 and $2.25 \mathrm{ml}$, respectively. The median number of seconds subjects took to drink the saccharin solution during conditioning were 180 (Group TAC), 187 (Group 1.8-90), 277 (Group 3.090), 144 (Group 1.8-360), 202 (Group 3.0-360), 185 (Group 1.8-1Day), and 202 (Group 3.0-1Day). Analysis of these drinking duration scores with the Mann-Whitney $U$ test ( $p<.05$, two-tailed) showed that Group 1.8-360 drank the saccharin in significantly less time than each of Groups 1.8-90, 3.0-90, 3.0360, and 3.0-1Day. Group 1.8-1Day also drank the solution in less time than Group 3.0-90. However, no other differences were statistically significant.

The amount of saccharin each group drank during the 20 -min postconditioning test is shown in Figure 1. The mean consumption of Group TAC was less than that of any other group, and intake among the various drug preexposed groups appeared to be influenced by both the preexposure dose and preexposure interval. The drinking scores of the preexposed subjects were first analyzed with a 2 (dose) by 3 (interval) analysis of variance which indicated a significant effect of the preexposure interval $[\mathrm{F}(2,54)=18.0, \mathrm{p}<.01]$ and $\mathrm{a}$ significant Interval by Dose interaction $[\mathrm{F}(2,54)=5.0$, 


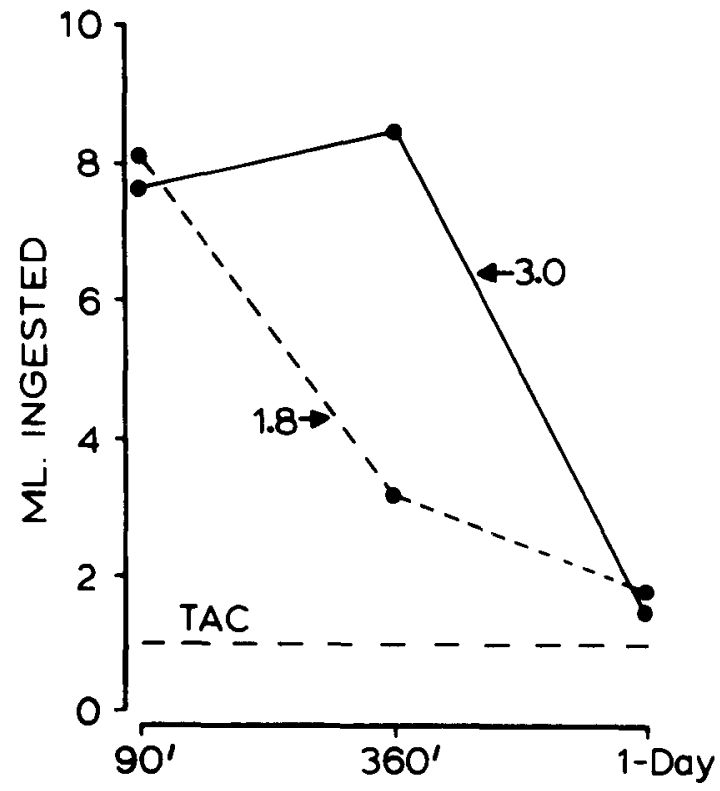

PREEXPOSURE INTERVAL

Figure 1. Mean saccharin test intakes in Experiment 1 for independent groups which received either a 1.8 - or a $3.0-\mathrm{mEq} / \mathrm{kg}$ lithium injection $90 \mathrm{~min}, 360 \mathrm{~min}$, or 1 day before saccharin conditioning. The dashed horizontal line represents the mean intake of Group TAC which received saccharin conditioning in the absence of lithium preexposure.

$p<.01]$. The main effect of preexposure dose, however, did not reach conventional levels of significance $[\mathrm{F}(1,54)=3.1, \mathrm{p}<.10]$.

The test intakes of the lithium preexposed groups, together with the intakes of the nonpreexposed Group TAC, were also evaluated with a one-way analysis of variance which yielded a significant effect of Groups $[F(6,63)=11.9, p<.01]$. Subsequent comparisons of the intake of each preexposed group to the intakes of the control Group TAC with the Dunnet test ( $p<.05$, two-tailed) indicated that only Groups 1.8-90, 3.0-90, and 3.0-360 drank significantly more than Group TAC.

It is important to note that the weaker saccharin aversions evident in Groups 1.8-90, 3.0-90, and 3.0360 as compared to Group TAC cannot be attributed to differences in saccharin intake during conditioning produced by the preexposure injection. The mean conditioning saccharin intake in each of Groups 1.8-90, 3.0-90, and TAC was $2.9 \mathrm{ml}$, and Group 3.0-360 had a mean intake of $3.0 \mathrm{ml}$. Furthermore, despite the preexposure lithium injection, Groups 1.8-90, 3.0-90, and 3.0-360 did not take significantly longer to drink the saccharin during conditioning than Groups TAC (see above).

\section{Discussion}

The present findings demonstrate that a preconditioning lithium exposure attenuates taste-aversion learning only if it is given less than $24 \mathrm{~h}$ before the aversion conditioning trial. This observation confirms previous reports of a transient/proximal US-preexposure effect in this response system (Domjan, 1978; Domjan \& Best, 1977).

The present findings also indicate that the interference with conditioning persists longer if the dose of the initial lithium injection is increased. A 3.0$\mathrm{mEq} / \mathrm{kg}$ dose of lithium disrupted conditioning with both 90 - and 360 -min preexposure intervals, but a $1.8-\mathrm{mEq} / \mathrm{kg}$ injection produced a significant interference effect only if it was given 90 min before conditioning. Earlier investigations had shown that higher doses of proximal drug-preexposure produce greater disruptions of conditioning (Cannon et al., 1975; Domjan, 1978). The present experiment extends these findings by showing that the interfering effects of higher preexposure doses also last longer.

Even though increasing the dose of the preexposure injection prolonged the disruptive effects of this injection on conditioning, there was no discernible effect of even the $3.0-\mathrm{mEq} / \mathrm{kg}$ preexposure dose when the conditioning trial occurred a day later. This outcome is inconsistent with previous reports of interference with aversion learning produced by 3.0 and $2.4 \mathrm{mEq} / \mathrm{kg}$ lithium given $24 \mathrm{~h}$ or more before conditioning (Braveman, 1975; Cannon et al., 1975). Although we are not certain of the source of this discrepancy, it is possible that the salience of exteroceptive cues differed across these experiments. Since it has been demonstrated that exteroceptive cues are capable of influencing the magnitude of a lithiummediated US-preexposure effect (e.g., Batson \& Best, 1979; Rudy, Iwens, \& Best, 1977; Willner, 1978), differences in the associability of exteroceptive cues with lithium may be important.

\section{EXPERIMENT 2}

The interference with conditioning produced by proximal US preexposure is inversely related to the interval between preexposure and conditioning (Experiment 1; Domjan \& Best, 1977). The malaise produced by the preexposure drug treatment probably has a similar time course (e.g., Domjan, 1977), and this coincidence may be responsible for the proximal preexposure phenomenon. It may be, for example, that the perceived properties of saccharin are altered by the drug state. Such alterations may then result in a generalization decrement when subjects treated with the preconditioning lithium exposure are tested later with saccharin in the normal state.

If the proximal US-preexposure phenomenon is due to a generalization decrement produced by changes in drug state, the effect should not be evident if the postconditioning test is preceded by drug treatment in the same manner as the conditioning trial. Experiment 2 was designed to evaluate 
this possibility. Preexposed subjects were injected with lithium $30 \mathrm{~min}$ before conditioning and received a similar lithium injection $30 \mathrm{~min}$ before their postconditioning test. In contrast, control subjects received the drug preexposure only before the test session. Since the pretest lithium injection was expected to reduce drinking during the test session (Domjan, 1977), the postconditioning test was extended to $60 \mathrm{~min}$. For one set of groups, all lithium injections were $1.8 \mathrm{mEq} / \mathrm{kg}$; for another set of subjects, the injections were $1.2 \mathrm{mEq} / \mathrm{kg}$.

\section{Method}

Twenty-one female (150-250 g) and 17 male (200-300 g) SpragueDawley rats were individually housed with continuous access to Purina Chow and 20-min daily access to water. Saccharin aversion conditioning was conducted on the 9th day after the beginning of the water-deprivation schedule. Subjects were assigned to four groups balanced as closely as possible for weight and gender. The 10 subjects in Group 30-H received two high-dose lithium injections (each $1.8 \mathrm{mEq} / \mathrm{kg}$ of a .15-M lithium chloride solution) on the conditioning day, one $30 \mathrm{~min}$ before a 10 -min period of access to $.15 \%$ sodium saccharin and the other $40 \mathrm{~min}$ after the beginning of this saccharin exposure. The 10 subjects in Group 30-L were treated the same way, except that they received two low-dose lithium injections (each $1.2 \mathrm{mEq} / \mathrm{kg}$ ). In contrast, control Groups $\mathrm{C}-\mathrm{H}$ and $\mathrm{C}-\mathrm{L}(\mathrm{ns}=9)$ received only the lithium injection $40 \mathrm{~min}$ after the beginning of the saccharin exposure. Group C-H received the high lithium dose $(1.8 \mathrm{mEq} / \mathrm{kg})$ and Group C-L received the low dose $(1.2 \mathrm{mEq} / \mathrm{kg})$. Furthermore, the saccharin consumption of each subject in Groups C-H and $\mathrm{C}-\mathrm{L}$ was limited to the mean saccharin intakes of Groups $30-\mathrm{H}$ $(6.3 \mathrm{ml})$ and $30-\mathrm{L}(9.4 \mathrm{ml})$, respectively. The $30-\mathrm{min}$ daily access to water was presented $1.5-2.5 \mathrm{~h}$ after the last lithium injection on the conditioning day. Five to 6 days later, each subject was again injected with lithium and received, starting 30 min later, a 60 -min one-bottle test with the saccharin solution. The dose of lithium injected on the test day was the same as the dose each subject had received during the conditioning trial. Intakes during the test session were recorded at 10 -min intervals.

\section{Results}

The mean saccharin intakes of each group during successive 10-min periods of the postconditioning test are presented in Figure 2. Groups $30-\mathrm{H}$ and 30-L, which had been exposed to lithium shortly before the conditioning trial, drank more saccharin throughout the test session than Groups C-H and C-L, which had not received lithium preexposure. Evaluation of the total amount ingested during the test revealed a main effect of preconditioning US exposure $[\mathrm{F}(1,34)$ $=9.7, \mathrm{p}<.01]$. However, neither the main effect of lithium dose nor the Preexposure by Dose interaction was significant.

\section{Discussion}

The present results indicate that the deleterious effects of proximal US preexposure on taste-aversion conditioning are evident even if subjects are tested shortly after a lithium injection. If the US preexposure effect observed in previous experiments (Experiment 1; Domjan \& Best, 1977) had been the result of an

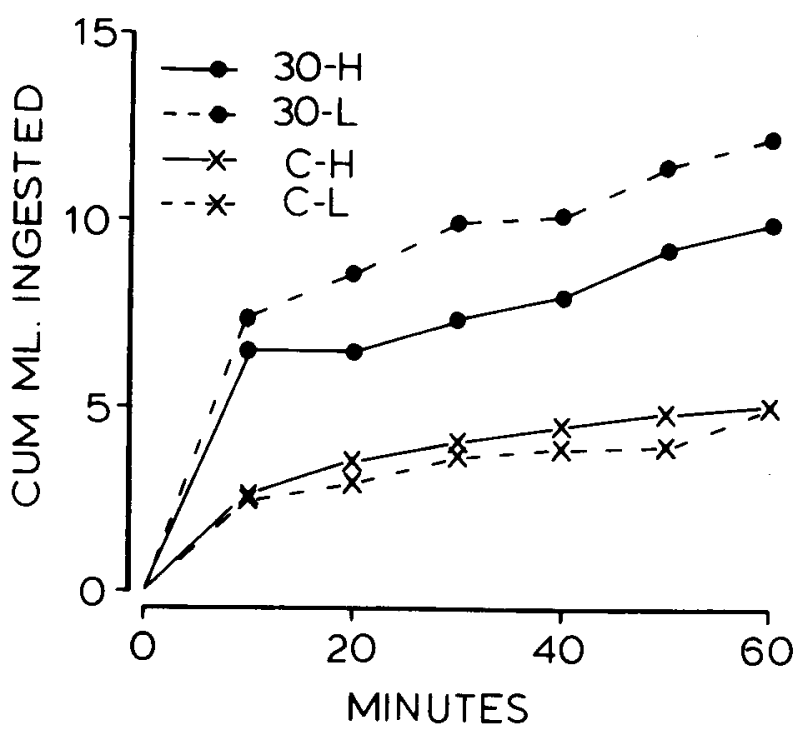

Figure 2. Mean cumulative saccharin consumption of various groups during the postconditioning test starting $30 \mathrm{~min}$ after a lithium injection in Experiment 2. Groups C-H and C-L previously received exposure to saccharin followed by an injection of lithium. Groups $30-\mathrm{H}$ and $30-\mathrm{L}$ were treated similarly except that they also received a lithium injection before the saccharin conditioning trial. The lithium doses were $1.8 \mathrm{mEq} / \mathrm{kg}$ for Groups $30-\mathrm{H}$ and $\mathrm{C}-\mathrm{H}$ and $1.2 \mathrm{mEq} / \mathrm{kg}$ for Groups $30-\mathrm{L}$ and $\mathrm{C}-\mathrm{L}$.

alteration of the perceived properties of saccharin by the drug treatment, the interference effect should not have occurred in subjects tested in the drug state. The fact that US preexposure resulted in weaker taste aversions even in subjects tested while under drug influence suggests that such preexposure does not disrupt the performance of a taste aversion by creating a stimulus generalization decrement. Rather, US preexposure appears to interfere directly with the conditioning process.

\section{EXPERIMENT 3}

It has been suggested that the durable/remote USpreexposure effect occurs because the preconditioning drug exposures are not signaled by a taste and therefore reduce the contingent relationship between tastes and drug effects (Cannon et al., 1975) or condition an interfering non-taste-drug expectancy (Mikulka, Leard, \& Klein, 1977). Consistent with this possibility, several investigators have found that aversion learning to a flavored solution is not attenuated by repeated remote drug preexposures if these drug treatments are signaled by another taste solution (e.g., Mikulka et al., 1977; Revusky, Parker, Coombes, $\&$ Coombes, 1976). Thus, the durable/remote USpreexposure effect can be reduced by pairing the preconditioning drug treatments with a taste different from the flavor to be used in the subsequent conditioning trial. Experiment 3 was designed to determine 
whether this manipulation similarly reduces the transient/proximal US-preexposure effect.

To demonstrate the transient/proximal preexposure phenomenon, one group of subjects received an unsignaled lithium injection $3 \mathrm{~h}$ before a saccharin conditioning trial. For another group, the lithium preexposure injection was paired with access to a novel vinegar solution so that the US preexposure would not reduce the contingency between tastes and drug effects. The vinegar solution was selected because previous research had indicated that little, if any, stimulus generalization occurs between the taste of vinegar and the saccharin taste used during the later conditioning trial (Domjan, 1975). Nevertheless, Experiment 3 also included various control groups to assess possible stimulus generalization and overshadowing produced by the introduction of the vinegar solution in the proximal US-preexposure procedure.

\section{Method}

Fifty-four naive male Holtzman rats, $160-350 \mathrm{~g}$, were individually housed as in Experiment 1. Access to water was restricted $1020 \mathrm{~min}$ daily for 12 days before the start of the experiment. On the final preexperimental day, the subjects were distributed to form six groups ( $n$ s $=9$ ), counterbalanced as closely as possible for baseline water intake and weight.

On Day 1 , approximately $4 \mathrm{~h}$ prior to the normal drinking period, animals in Group V-Li/S-Li received access to $12 \mathrm{ml}$ of a $3 \%$ vinegar solution (cider vinegar diluted to $5 \%$ acidity with tap water) for $5 \mathrm{~min}$. Immediately after this taste exposure, each rat was picked up, injected with $1.8 \mathrm{mEq} / \mathrm{kg} .15 \mathrm{M}$ lithium chloride, and then returned to its home cage. One hundred and eighty minutes later, the subjects received $12 \mathrm{ml}$ of a $.15 \%$ sodium saccharin solution for $5 \mathrm{~min}$. Twenty-five minutes following completion of the 5-min saccharin-drinking session, each animal was given a second $1.8-\mathrm{mEq} / \mathrm{kg}$ lithium injection, and $2 \mathrm{~h}$ following this injection, the subjects received water for $20 \mathrm{~min}$.

Groups $\mathrm{Li} / \mathrm{S}-\mathrm{Li}, \mathrm{V} / \mathrm{S}-\mathrm{Li}$, and $\mathrm{Na} / \mathrm{S}-\mathrm{Li}$ were treated identically to Group V-Li/S-Li, with the following exceptions: Group $\mathrm{Li}$ / $\mathrm{S}$-Li did not receive vinegar prior to the initial lithium injection, Group V/S-Li received the vinegar exposure but was not injected following this fluid presentation, and Group $\mathrm{Na} / \mathrm{S}-\mathrm{Li}$ received isotonic saline injections (equivalent by volume) $180 \mathrm{~min}$ prior to the saccharin-lithium trial. Two additional groups were included to control for generalization of conditioned aversion from the vinegar to the saccharin solution. Neither of these groups received the saccharin-lithium pairing given all other groups: Group V-Li received only a vinegar-lithium trial identical to that administered to Group V-Li/S-Li, and Group V-Na received only vinegar exposure paired with an injection of isotonic saline.

On Day 2, the animals in all six groups received water for 20 min at the regular drinking time. On Day 3 , each animal received a $20-\mathrm{min}$ one-bottle test with the saccharin solution during the normal drinking period. Immediately following this test, the animals received exposure to water for $20 \mathrm{~min}$. Twentyfour hours later, on Day 4, all animals received a 20-min vinegar test. All intakes were measured to the nearest $.5 \mathrm{ml}$.

\section{Results}

A one-way analysis of variance computed on the conditioning day vinegar intakes did not reveal a significant difference among the groups which received vinegar [Groups V-Li/S-Li, V/S-Li, V-Li; F $(2,24)$
$<1.0$; mean intakes $9.5-9.9 \mathrm{ml}$. There was, however, a significant difference among the four groups which received saccharin on the conditioning day [Groups $\mathrm{V}-\mathrm{Li} / \mathrm{S}-\mathrm{Li}, \mathrm{V} / \mathrm{S}-\mathrm{Li}, \mathrm{Li} / \mathrm{S}-\mathrm{Li}, \mathrm{Na} / \mathrm{S}-\mathrm{Li} ; \mathrm{F}(3,32)=3.06$, $\mathrm{p}<.05]$. Subsequent comparisons with the NewmanKeuls test $(p<.05$, two-tailed) indicated that Group $\mathrm{V}$-Li/S-Li drank less saccharin (mean $=9.0 \mathrm{ml}$ ) than Group V $/ \mathrm{S}-\mathrm{Li}($ mean $=10.9 \mathrm{ml})$. No other group differences were statistically significant. (The mean intakes of Groups $\mathrm{Li} / \mathrm{S}-\mathrm{Li}$ and $\mathrm{Na} / \mathrm{S}$ - $\mathrm{Li}$ were $10.3 \mathrm{ml}$ and $10.4 \mathrm{ml}$, respectively.)

The amount of saccharin each group drank during the postconditioning test on Day 3 is summarized in Figure 3. Group $\mathrm{Na} / \mathrm{S}-\mathrm{Li}$, which received saccharin conditioning without prior exposure to either vinegar or lithium, showed the strongest saccharin aversions. Somewhat weaker aversions were evident in subjects which had been exposed only to vinegar before saccharin conditioning (Group V/S-Li). In contrast, preexposure either to lithium (Group $\mathrm{Li} / \mathrm{S}-\mathrm{Li}$ ) or to both vinegar and lithium (Group V-Li/S-Li) substantially attenuated saccharin conditioning. Groups $\mathrm{V}$-Li and $\mathrm{V}-\mathrm{Na}$, which did not have saccharin paired with lithium, drank the greatest quantity of saccharin during the test session.

A one-way analysis of variance computed on the saccharin test intakes confirmed the existence of group differences $[F(5,48)=17.09, p<.01]$. Subsequent Newman-Keuls tests ( $p<.05$, two-tailed) showed that Group $\mathrm{Na} / \mathrm{S}$-Li drank significantly less saccharin than each of the other groups except Group $\mathrm{V} / \mathrm{S}$ - $\mathrm{Li}$, which also drank significantly less saccharin than each of Groups V-Li/S-Li, V-Li, and V-Na. Groups V-Li/S-Li and Li/S-Li were not significantly different from each other, but each of these groups drank significantly less saccharin than each of

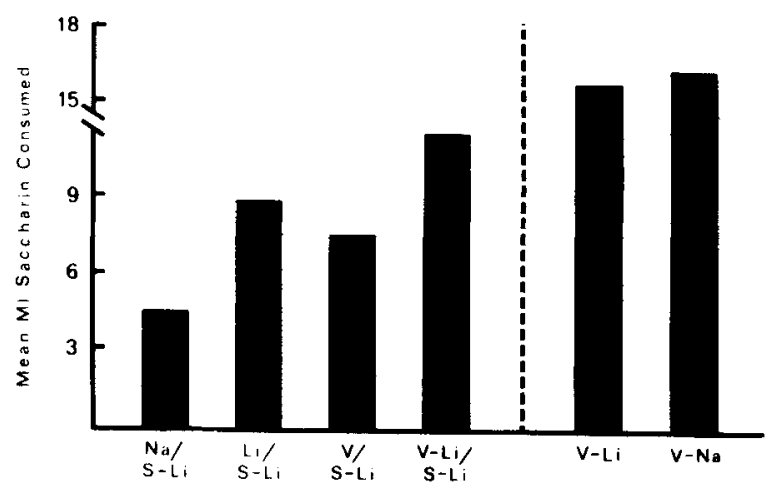

Figure 3. Mean saccharin test intakes in Experiment 3. Four groups received saccharin conditioning $3 \mathrm{~h}$ after an injection of physiological saline (Group $\mathrm{Na} / \mathrm{S}-\mathrm{L}$ i), injection of lithium (Croup $\mathrm{Li} / \mathrm{S}-\mathrm{Li}$ ), access to vinegar (Group $\mathrm{V} / \mathrm{S}-\mathrm{L}, \mathrm{i})$, or access to vinegar paired wilh lithium ( $($ roup $V-1, j / S-L i)$. The remaining I wo groups did not receive saceharin conditioning but were exposed to vinegar followed by either an injection of lithium (Ciroup V-lii) or saline (Group V.Na). 
Groups V-Li and V-Na. No other group differences proved to be statistically significant.

The saccharin test intakes of Groups $\mathrm{Na} / \mathrm{S}-\mathrm{Li}$, $\mathrm{V} / \mathrm{S}-\mathrm{Li}, \mathrm{Li} / \mathrm{S}-\mathrm{Li}$, and $\mathrm{V}-\mathrm{Li} / \mathrm{S}-\mathrm{Li}$ were also evaluated with a 2 by 2 analysis of variance (presence vs. absence of preexposure to vinegar, and presence vs. absence of preexposure to lithium) to determine whether the effects of drug preexposure on saccharin aversion learning were modified by preexposure to the vinegar flavor. This analysis revealed that subjects preexposed to vinegar (Groups V/S-Li and V-Li/S-Li) learned weaker saccharin aversions than subjects which did not receive such preexposure (Groups $\mathrm{Na} / \mathrm{S}-\mathrm{Li}$ and $\mathrm{Li} / \mathrm{S}-\mathrm{Li})[\mathrm{F}(1,32)=11.35, \mathrm{p}<.01]$. Similarly, subjects preexposed to lithium (Groups $\mathrm{Li} / \mathrm{S}-\mathrm{Li}$ and $\mathrm{V}-\mathrm{Li} / \mathrm{S}-\mathrm{Li}$ ) learned weaker aversions than those which had not been preexposed to the drug (Groups $\mathrm{Na} / \mathrm{S}-\mathrm{Li}$ and $\mathrm{V} / \mathrm{S}-\mathrm{Li})[\mathrm{F}(1,32)=12.88$, $\mathrm{p}<.01]$. However, there was no significant interaction between the flavor and drug preexposure manipulations $(\mathrm{F}<1.0)$.

The mean vinegar intakes of subjects during the vinegar test administered on Day 4 were $1.5 \mathrm{ml}$ (Group V-Li/S-Li), $12.5 \mathrm{ml}$ (Group Li/S-Li), $8.0 \mathrm{ml}$ (Group Na/S-Li), $12.0 \mathrm{ml}$ (Group V/S-Li), $2.0 \mathrm{ml}$ (Group V-Li), and $12.7 \mathrm{ml}$ (Group V-Na). A one-way analysis showed a significant effect of Groups $[F(5,48)=12.39, \mathrm{p}<.01]$. Newman-Keuls tests ( $<<.05$, two-tailed) showed that Groups V-Li/S-Li and V-Li drank significantly less vinegar than each of the other groups. No other group differences were significant. Thus, only subjects which had vinegar paired with lithium subsequently evidenced an aversion to vinegar.

\section{Discussion}

Consistent with previous observations (Experiment 1; Domjan, 1978; Domjan \& Best, 1977), a single lithium injection given $3 \mathrm{~h}$ before saccharin conditioning (Group Li/S-Li) greatly attenuated saccharin aversion learning. Furthermore, this interference with conditioning occurred even if the lithium preexposure was paired with a novel vinegar flavor (Group V-Li/S-Li). In fact, the mean saccharin intakes of Group V-Li/S-Li exceeded, although not significantly, the saccharin intakes of Group $\mathrm{Li} / \mathrm{S}$ Li. Thus, there was no evidence that pairing the preexposure lithium injection with vinegar reduced the disruptive effects of proximal drug preexposure on saccharin conditioning.

It has been suggested that drug preexposure attenuates conditioning because it reduces the contingency between taste and drug effects or conditions a non-taste-drug expectancy (Cannon et al., 1975; Mikulka et al., 1977). Consistent with these hypotheses, several investigators have reported that the deleterious effects of drug injections given several days before a taste-drug conditioning trial can be reduced by pairing the preexposure injections with another taste (e.g., Mikulka et al., 1977; Revusky et al., 1976). The presentation of a flavor with the preexposure drug treatments presumably insures both that there is no reduction in the contingent relationship of taste and drug effects and that the subjects do not learn a nontaste-drug expectancy as a result of drug preexposure. The present results show that the disruptive effects on conditioning of a drug treatment less than 1 day before conditioning is not reduced by pairing a distinctive flavor with the preexposure injection. Thus, in contrast to the remote US preexposure effect, the proximal US preexposure effect appears to be immune to manipulations designed to insure that preexposure does not reduce the contingency between taste and drug effects.

It may be suggested that presenting vinegar immediately before the proximal lithium-preexposure injection failed to reduce the interference with saccharin conditioning because the vinegar exposure occurred close enough to the saccharin presentation to produce overshadowing (Kamin, 1968, 1969; Pavlov, 1927, pp. 141-144;) of the saccharin flavor. Consistent with this interpretation, the factorial analysis of the effects of vinegar and lithium preexposure revealed a significant main effect of vinegar preexposure. However, the main effect of lithium preexposure was also significant. This indicates that even though the vinegar exposure several hours before conditioning contributed to a reduction in the saccharin-lithium association, lithium preexposure provided an important additional source of interference with conditioning.

It is also important to note that stimulus generalization between vinegar and saccharin probably did not contribute much, if anything, to the saccharin test intakes observed in the present study. Groups $\mathrm{V}-\mathrm{Li}$ and $\mathrm{V}-\mathrm{Na}$ had comparable saccharin test intakes, and these two groups drank more saccharin than each of the other groups. The absence of an aversion to saccharin in Group V-Li confirms previous failures to observe substantial generalization between the taste of saccharin and vinegar solutions (Domjan, 1975).

Finally, it is interesting to note that even though lithium preexposure (Groups V-Li/S-Li and Li/S-Li) attenuated saccharin conditioning, the interference was not complete. Both lithium-preexposed groups drank significantly less saccharin during the test session than Groups V-Li and V-Na, which had not received saccharin aversion conditioning.

\section{GENERAL DISCUSSION}

Taste-aversion learning is disrupted if the subjects are given a single exposure to the unconditioned 
stimulus shortly before the conditioning trial, and this interference effect is inversely related to the interval between preexposure and conditioning. Previous research had shown that this deleterious effect of proximal US preexposure is evident even if the preexposure US treatment is otherwise effective in producing a "backward" conditioned saccharin aversion (Domjan \& Best, 1977, Experiment 2). The interfering effects of proximal US preexposure have also been observed whether the conditioning drug treatment is administered before or after the CS flavor during training (Domjan, 1978). The present experiments extend these findings by showing that the proximal US-preexposure effect occurs over a range of preexposure drug doses, whether or not subjects are tested for aversion learning following a drug injection, and whether or not the preexposure US treatment is paired with a novel flavor. The present findings, together with earlier research, show that the proximal US-preexposure phenomenon occurs in a remarkably wide variety of situations.

The large range of situations which permit observation of the proximal US-preexposure effect presents a challenge for explanations of the phenomenon. However, all of the data are consistent with at least two different types of mechanisms. One of these assumes that proximal US preexposure somehow reduces the effectiveness of the conditioning US presentation and therefore creates smaller unconditioned responses following taste presentation during the conditioning trial. The other assumes that the preexposure US treatment makes the conditioned stimulus (CS) flavor less available for association, and this is responsible for the interference with learning.

As noted previously (Domjan, 1978; Domjan \& Best, 1977), explanation of the proximal US-preexposure phenomenon in terms of a reduction in the unconditioned responses which occur during the conditioning trial is consistent with two prominent contemporary theories. The opponent-process theory of motivation (Solomon, 1977; Solomon \& Corbit, 1974) states that biologically powerful stimuli such as drug treatments produce biphasic affective changes. The initial effects of a drug are assumed to be followed by an opponent aftereffect which blocks reinstatement of the initial affective state. Therefore, it is predicted that a second drug injection will be less effective if it is presented during the opponent aftereffect of the first injection than if it is presented after this opponent process has decayed. Likewise, one aspect of an information processing model proposed by Wagner $(1976,1978)$ is relevant to an interpretation of the overall pattern of results observed in the present experiments. According to this framework, presentation of a stimulus transiently "primes" or represents the event in a short-term memory system (i.e., self-generated priming). If the primed event is then repeated while the representation of the initial exposure is still active, the effectiveness of the second presentation is assumed to be reduced. Conditioning decrements consistent with the implications of self-generated priming occurred in each of the three experiments reported here, and have also been demonstrated in a related design employing a shock US (Terry, 1976).

In contrast to attempts to explain the proximal preexposure effect in terms of a reduction in the effectiveness of the conditioning US presentation, it may be suggested that proximal US preexposure makes the CS flavor less available for association. The lithium unconditioned stimulus used in proximal preexposure in the present experiments no doubt provides numerous and intense sensory experiences. These sensations could make the CS flavor less available for association because of either "attentional" or associative competition. Assuming that stimulus processing requires access to an attentional or short-term memory system of limited capacity, proximal US preexposure could interfere with conditioning by dominating the resources of the attentional or STM system and thereby preventing the amount of processing of the flavor CS which is necessary for strong conditioning. The preexposure presentation of the US may also compete with the CS for association with the conditioning presentation of the US given later. This latter mechanism is analogous to the associative competition which is usually assumed to be responsible for the more familiar CS overshadowing phenomenon (Mackintosh, 1974, p. 50).

\section{REFERENCES}

Batson, J. D., \& BEST, P. J. Drug preexposure effects in flavor aversion learning: Associative interference by conditioned environmental stimuli. Journal of Experimental Psychology: Animal Behavior Processes, 1979, 5, 273-283.

Braveman, N. S. Formation of taste aversions in rats following prior exposure to sickness. Learning and Motivation, 1975, $6,512-534$

Cannon, D. S., Berman, R. F., Baker, T. B., \& Atrinson, C. A. Effect of preconditioning unconditioned stimulus experience on learned taste aversions. Journal of Experimental Psychology: Animal Behavior Processes, 1975, 1, 270-284.

Domjan, M. Poison-induced neophobia in rats: Role of stimulus generalization of conditioned taste aversions. Animal Learning \& Behavior, 1975, 3, 205-211.

DomJan, M. Selective suppression of drinking during a limited period following aversive drug treatment in rats. Journal of Experimental Psychology: Animal Behavior Processes, 1977, 3, 66-76.

Dom.jan, M. Effects of proximal unconditioned stimulus preexposure on ingestional aversions learned as a result of taste presentation following drug treatment. Animal Learning \& Behavior, 1978, 6, 133-142.

Domjan, M., \& Best, M. R. Paradoxical effects of proximal unconditioned stimulus preexposure: Interference with and conditioning of a taste aversion. Journal of Experimental Psychologv: Animal Behavior Processes, 1977, 3, 310-321. 
Gamzu, E. The multifaceted nature of taste-aversion inducing agents: Is there a single common factor? In L. M. Barker, M. R. Best, \& M. Domjan (Eds.), Learning mechanisms in food selection. Waco, Tex: Baylor University Press, 1977.

KAMIN, L. J. "Attention-like"' processes in classical conditioning. In M. R. Jones (Ed.), Miami symposium on the prediction of behavior: Aversive stimulation. Miami, Fla: University of Miami Press, 1968.

KAMIN, L. J. Predictability, surprise, attention and conditioning. In R. Church \& B. A. Campbell (Eds.), Punishment and aversive behavior. New York: Appleton-Century-Crofts, 1969.

Mikulka, P. J., Leard, B., \& KLein, S. B. Illness-alone exposure as a source of intereference with the acquisition and retention of a taste aversion. Journal of Experimental Psychology: Animal Behavior Processes, 1977, 3, 189-201.

Pavlov, I. P. Conditioned reflexes. Oxford: Oxford University Press, 1927.

MACKintosh, N. J. The psychology of animal learning. London: Academic Press, 1974.

Revusky, S. H., Parker, L., Coombes, J., \& Coombes, S. Rat data which suggest alcoholic beverages should be swallowed during chemical aversion therapy, not just tasted. Behavior Research and Therapy, 1976, 14, 189-194.

Rudy, J. W., IWENS, J., \& BEst, P. J. Pairing novel exterceptive cues and illness reduces illness-induced taste aversions. Journal of Experimental Psychology: Animal Behavior Processes, 1977, 3, 14-25.
Solomon, R. L. An opponent-process theory of motivation: The affective dynamics of drug addiction. In J. D. Maser \& M. E. P. Seligman (Eds.), Psychopathology: Experimental models. San Francisco: Freeman, 1977

Solomon, R. L., \& Corbit, J. D. An opponent-process theory of motivation: 1. Temporal dynamics of affect. Psychological Review, 1974, 81, 119.145.

TERRY, W. S. Effects of priming unconditioned stimulus representation in short-term memory on Pavlovian conditioning. Journal of Experimental Psychology: Animal Behavior Processes, 1976, 2, 354-369.

WAGNER, A. R. Priming in STM: An information processing mechanism for self-generated or retrieval-generated depression of performance. In T. J. Tighe \& R. N. Leaton (Eds.), Habituation: Perspectives from child development, animal behavior, and neurophysiology. Hillsdale, N.J: Erlbaum, 1976.

WAGNER, A. R. Expectancies and the priming of STM. In S. H. Hulse, H. Fowler, \& W. K. Honig (Eds.), Cognitive aspects of animal behavior. Hillsdale, N.J: Erlbaum, 1978.

Willner, J. A. Blocking of a taste aversion by prior pairings of exteroceptive stimuli with illness. Learning and Motivation, $1978,9,125-140$.

(Received for publication September 26, 1978; revision accepted April 3, 1979.) 